
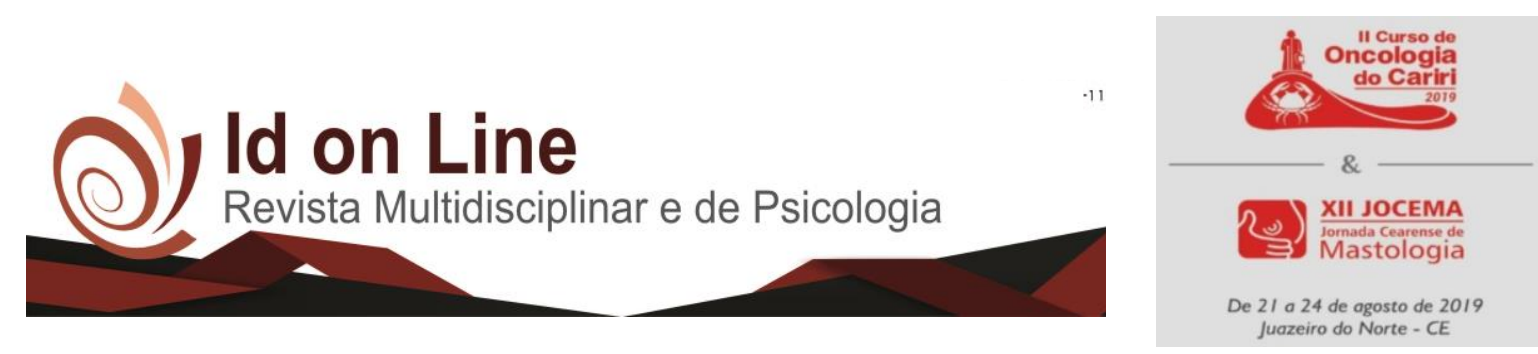

DOI: 10.14295/idonline.v13i46.2000

Resumo

\title{
PREVALÊNCIA DE CASOS E DE ÓBITOS ENVOLVENDO NEOPLASIAS MALIGNAS DO ESTÔMAGO NA MACRORREGIÃO DO CARIRI
}

\author{
Letícia Bezerra Morais ${ }^{1}$; Jonas Lima Pinho²; Laryza Souza Soares ${ }^{3}$; \\ Marcos Alexandre Casimiro de Oliveira ${ }^{4}$
}

Introdução: $O$ câncer de estômago é a terceira neoplasia mais comum nos homens e a quinta nas mulheres do Brasil, possui uma alta taxa de mortalidade, tendo sua causa associada a fatores hereditários e externos. Objetivo: Analisar a prevalência das neoplasias malignas do estômago na macrorregião do Cariri, associando os fatores de risco aos casos e óbitos. Métodos: Foi realizada uma pesquisa de abordagem qualitativa e quantitativa, com base na pergunta norteadora: quais fatores influenciam na incidência dos casos de neoplasias de estômago na macrorregião do Cariri? $\mathrm{Na}$ qual foi desenvolvida no período de julho de 2019, a partir dos bancos de dados da SciELO, utilizando os seguintes Descritores Controlados de Ciências da Saúde (DECS): neoplasia, estômago e fatores de risco. Foram selecionados 5 artigos que estavam de acordo com o objetivo da pesquisa e se enquadravam nos critérios de inclusão: artigos que responderam à pergunta guia e que possuíam os três descritores. Além disso, foram utilizados dados obtidos do Sistema de Informações sobre Mortalidade (SIM) do Ministério da Saúde, disponíveis no Departamento de Informática do Sistema Único de Saúde (Datasus). Os óbitos foram selecionados segundo a Classificação Estatística Internacional de Doenças e Problemas Relacionados à Saúde (CID): neoplasia maligna do estômago (CID-10) dos últimos 11 anos, com o registro de internações e de óbitos relacionados aos sexos feminino e masculino e à faixa etária. Resultados: Verificou-se que na macrorregião do Cariri, dados do Datasus expõem os óbitos por sexo durante o período de Fevereiro de 2008 a Maio de 2019, sendo possível observar 115 óbitos de pacientes do sexo masculino e 69 óbitos de pacientes do sexo feminino, totalizando 184 óbitos por neoplasia de estômago na macrorregião durante os 12 anos de registros na plataforma. Além disso, o levantamento revela um crescimento significativo da mortalidade por câncer de estômago a partir dos 60 anos de idade, em que a faixa etária de 60 a 64 apresentou 25 óbitos, sendo mais do que o dobro do número registrado entre a faixa etária de 50 a 54 anos (11 óbitos). Conclusão: Portanto, é notável que ainda há um crescimento expressivo dos casos de neoplasia de estômago na macrorregião do Cariri assim como dos números de óbito, com maior incidência entre os homens e os idosos a partir dos 60 anos. Esse número permanece alto devido aos hábitos de vida da população, que contribuem para o surgimento da neoplasia.

Palavras Chave: Estômago, Fatores de Risco, Neoplasia.

\footnotetext{
${ }^{1}$ Graduanda em Medicina pela Faculdade Santa Maria (FSM), Cajazeiras-PB.

${ }^{2}$ Graduando em Medicina pela Universidade Federal do Cariri (UFCA), Barbalha-CE.

${ }^{3}$ Graduanda em Medicina pela Faculdade de Medicina Estácio do Juazeiro do Norte (FMJ), Juazeiro do Norte- CE.

${ }^{4}$ Doutorando em Ciências Odontológicas pela Universidade Federal da Paraíba (UFPB) e Docente do Curso de Medicina pela Faculdade Santa Maria (FSM), Cajazeiras-PB.
} 


\section{Referências}

ARREGI, Miren Maite Uribe et al. Perfil clinico-epidemiológico das neoplasias de estomago atendidas no Hospital do Câncer do Instituto do Câncer do Ceará, no período de 2000-2004. Rev Bras Cancerol, v. 55, n. 2, p. 121-8, 2009. Avaliable from http://www1.inca.gov.br/rbc/n_55/ v02/pdf/05_artigo2.pdf>. access on 01 Aug 2019.

BARBOSA, I. R., de Souza, D. L., Bernal, M. M., \& do C C Costa, Í. (2015). Cancer mortality in Brazil: Temporal Trends and Predictions for the Year 2030. Medicine, 94(16), e746. Avaliable from <https://www.ncbi.nlm.nih.gov/pmc/articles/PMC4602680/>. Acess on 01 Aug. 2019. doi:10.1097/MD.0000000000000746.

BRITTO, Anna Valéria de. Câncer de estômago: fatores de risco. Cadernos de Saúde Pública, v. 13, p. S7-S13, 1997. Avaliable from https://www.scielosp.org/scielo.php?script=sci_arttext\& pid=S0102-311X1997000500002. access on 01 Aug. 2019.

GUERRA, Maximiliano Ribeiro et al . Magnitude e variação da carga da mortalidade por câncer no Brasil e Unidades da Federação, 1990 e 2015. Rev. bras. epidemiol., São Paulo, v. 20, supl. 1, p. 102-115, May 2017.

LACERDA, Kelly Cavalheiro et al . Mortalidade por câncer de estômago em Volta Redonda-RJ, 1981-2008. Epidemiol. Serv. Saúde, Brasília , v. 23, n. 3, p. 519-526, Sept. 2014 . Available from <http://www.scielo.br/scielo.php?script=sci_arttext\&pid=S22376222014000300519\&lng= en\&nrm=iso>. access on 08 July 2019. 